\title{
Microstructural and Mechanical Characteristics of AZ61 Magnesium Alloy Processed by High-Pressure Torsion*1
}

\author{
Yosuke Harai $^{1}$, Masaaki Kai ${ }^{1}$, Kenji Kaneko ${ }^{1}$, Zenji Horita ${ }^{1, * 2}$ and Terence G. Langdon ${ }^{2,3}$ \\ ${ }^{1}$ Department of Materials Science and Engineering, Faculty of Engineering, Kyushu University, Fukuoka 819-0395, Japan \\ ${ }^{2}$ Departments of Aerospace \& Mechanical Engineering and Materials Science, \\ University of Southern California, Los Angeles, CA 90089-1453, U.S.A. \\ ${ }^{3}$ Materials Research Group, School of Engineering Sciences, University of Southampton, Southampton SO17 1BJ, U.K.
}

\begin{abstract}
Experiments were conducted on an AZ61 magnesium alloy to evaluate the microstructural characteristics and the mechanical properties after processing by High-Pressure Torsion (HPT). The results show that processing by HPT produces excellent grain refinement with average grain sizes of $\sim 0.22$ and $\sim 0.11 \mu \mathrm{m}$ after processing at $423 \mathrm{~K}$ and room temperature, respectively. Tensile testing after HPT revealed the potential for achieving superplastic elongations with a maximum recorded elongation of $620 \%$ when testing at a temperature of $473 \mathrm{~K}$. Using microhardness measurements, it is demonstrated that the the microstructure gradually evolves with increasing torsional straining in HPT so that ultimately there is a reasonably homogeneous structure across the disk. [doi:10.2320/matertrans.ME200718]
\end{abstract}

(Received July 13, 2007; Accepted October 4, 2007; Published November 21, 2007)

Keywords: hardness, high-pressure torsion, magnesium alloy, superplasticity, ultrafine grains

\section{Introduction}

The grain size of a polycrystalline metal is an important parameter because it determines both the strength of the material at ambient temperatures and the ability to conduct superplastic forming operations at elevated temperatures. When the grain size lies within the low micrometer range, from $\sim 1$ to $\sim 10 \mu \mathrm{m}$, the material exhibits high strength and there is a potential for achieving high superplastic ductilities when pulling in tension at high temperatures.

Very recently, considerable attention has focused on the fabrication of metallic alloys with grain sizes within the submicrometer range. For grain sizes lying below $1000 \mathrm{~nm}$, these are termed ultrafine-grained materials ${ }^{1)}$ and they are most readily produced by processing through the application of severe plastic deformation (SPD). ${ }^{2)}$ Several different SPD processing techniques are now available but the most important are Equal-Channel Angular Pressing (ECAP), ${ }^{3)}$ High-Pressure Torsion ${ }^{4)}$ and Accumulative Roll-Bonding $(\mathrm{ARB}){ }^{5)}$

Several investigations have shown that HPT is especially effective in producing materials with very small grain sizes. ${ }^{6}$ For example, detailed experiments on pure Ti and Ti-based alloys demonstrated that HPT was the most effective procedure for achieving grain refinement with reported average grain sizes after HPT of $\sim 30 \mathrm{~nm} .{ }^{7)}$ However, despite the advantage of HPT, most experimental investigations to date have concentrated on the use of ECAP.

When materials are processed by ECAP, early experiments showed the feasibility of attaining exceptionally high superplastic elongations provided the grain structure is reasonably stable at elevated temperatures. ${ }^{8}$ More recently, there have been numerous reports of the advent of superplasticity in materials processed by ECAP and a comprehensive tabu-

\footnotetext{
${ }^{* 1}$ This Paper was Originally Published in Japanese in J. Japan Inst. Metals 71 (2007) 213-217.

${ }^{* 2}$ Corresponding author, E-mail: horita@zaiko.kyushu-u.ac.jp
}

lation is now available documenting all of the reports of superplastic flow in materials processed by ECAP. ${ }^{9)}$ These various reports are concentrated primarily on aluminumbased alloys but they include also a small number of reports documenting superplasticity in other materials such as $\mathrm{Cu}$ and $\mathrm{Mg}$ alloys.

The present investigation was initiated with three specific objectives.

First, although there was a very early report of the successful application of HPT to a magnesium alloy with the production of a grain size lying in the range of $\sim 110$ $150 \mathrm{~nm},{ }^{10)}$ very little subsequent work has focused on the application of HPT to Mg-based alloys and instead much of the emphasis has centered on the application of HPT to Al, $\mathrm{Cu}$ and $\mathrm{Ni}$ alloys. Accordingly, the present investigation was designed to evaluate the microstructural and mechanical characteristics of a commercial AZ61 magnesium alloy after processing by HPT.

Second, magnesium alloys are generally difficult to process by SPD and this means that special procedures are required to effectively process these alloys using ECAP. ${ }^{11)}$ For example, experiments on the AZ31 alloy using ECAP showed it was feasible to successfully press the alloy only at temperatures above $473 \mathrm{~K}$ when pressing without a backpressure whereas the same alloy was successfully pressed at $373 \mathrm{~K}$ when a back-pressure was incorporated into the system. ${ }^{12)}$ Since processing by HPT involves the imposition of a high initial pressure, it is reasonable to anticipate the alloy may be effectively processed by HPT at lower temperatures including at room temperature. Thus, a second important objective was to evaluate the feasibility of successfully applying HPT to the AZ61 alloy over a range of temperatures.

Third, there are only limited reports to date of the occurrence of superplastic elongations after processing by HPT, with reports of elongations of $\sim 500 \%$ and $\sim 570 \%$ for an $\mathrm{Al}-3 \% \mathrm{Mg}-0.2 \% \mathrm{Sc}$ alloy ${ }^{13)}$ and an $\mathrm{Al}-2024$ alloy, ${ }^{14)}$ respectively. An additional objective was therefore to 


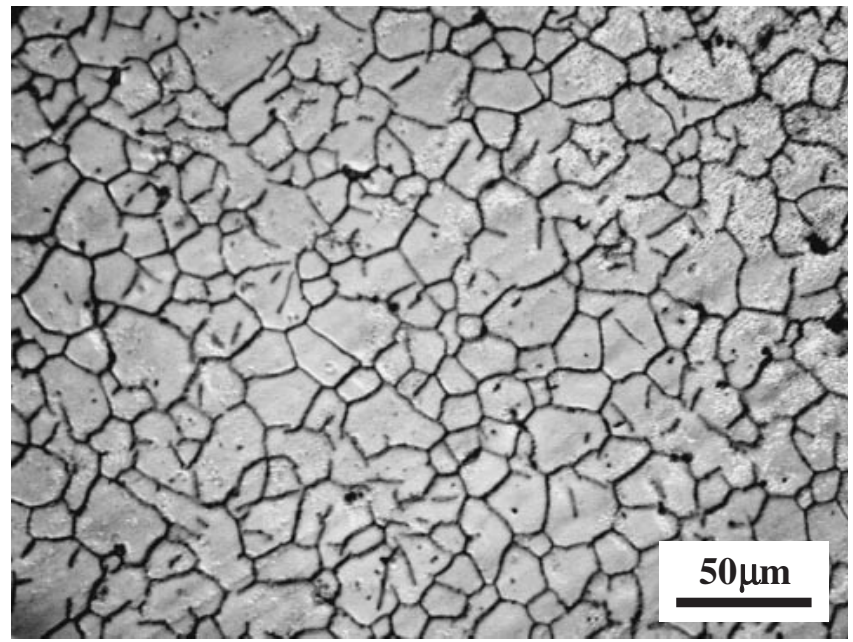

Fig. 1 Optical micrograph of the as-extruded AZ61 alloy showing an initial grain size of $\sim 22 \mu \mathrm{m}$.

evaluate whether it is feasible to achieve superplastic ductilities in the AZ61 alloy after processing by HPT. In this connection, it should be noted there are reports of elongations up to $\sim 1190 \%^{15)}$ and $\sim 1320 \%{ }^{16}$ ) in the AZ61 alloy after processing by ECAP.

\section{Experimental Material and Procedures}

The experiments were conducted using a commercial AZ61 alloy having a composition, in mass $\%$, of $6.40 \% \mathrm{Al}$, $0.74 \% \mathrm{Zn}, 0.35 \% \mathrm{Mn}, 0.0012 \% \mathrm{Ni}, 0.001 \% \mathrm{Cu}, 0.001 \% \mathrm{Fe}$, $0.015 \% \mathrm{Si}$ with the balance as $\mathrm{Mg}$. Earlier experiments on pure magnesium and $\mathrm{Mg}$ alloys showed that it is often difficult to satisfactorily process these materials in ECAP when they are used in an as-cast form ${ }^{17)}$ but excellent processing may be achieved when the alloys are extruded prior to ECAP in a process designated EX-ECAP. ${ }^{18,19)}$ In the present investigation, the alloy was received as an extruded rod with a diameter of $15 \mathrm{~mm}$ and it was then machined to a diameter of $10 \mathrm{~mm}$. Figure 1 shows the microstructure of the as-extruded AZ61 alloy and it is apparent that the grains are reasonably equiaxed, uniformly distributed and there was an average initial grain size of $\sim 22 \mu \mathrm{m}$.

Processing by HPT was achieved by cutting thin disks from the extruded rod with diameters of $10 \mathrm{~mm}$ and thicknesses of $0.8 \mathrm{~mm}$. These disks were processed in the facility shown in Fig. 2 where the sample is placed between two anvils, subjected to a pressure, and then torsionally strained by rotation of the lower anvil. The HPT facility was described in detail earlier ${ }^{13)}$ but it is important to note these processing conditions correspond to constrained HPT where the sample is held in place in a cavity and therefore the straining occurs effectively in the presence of a backpressure. $^{20,21)}$ The processing was conducted at room temperature and at elevated temperatures of 373 and $423 \mathrm{~K}$ using a small heater placed around the anvils as shown on the right in Fig. 2. For all samples, the imposed pressure, $P$, was $3 \mathrm{GPa}$, the lower anvil was rotated at a speed of $1 \mathrm{rpm}$ and the samples were subjected to totals, $N$, of 1, 3, 5 and 7 turns.

The equivalent von Mises strain in HPT is given by

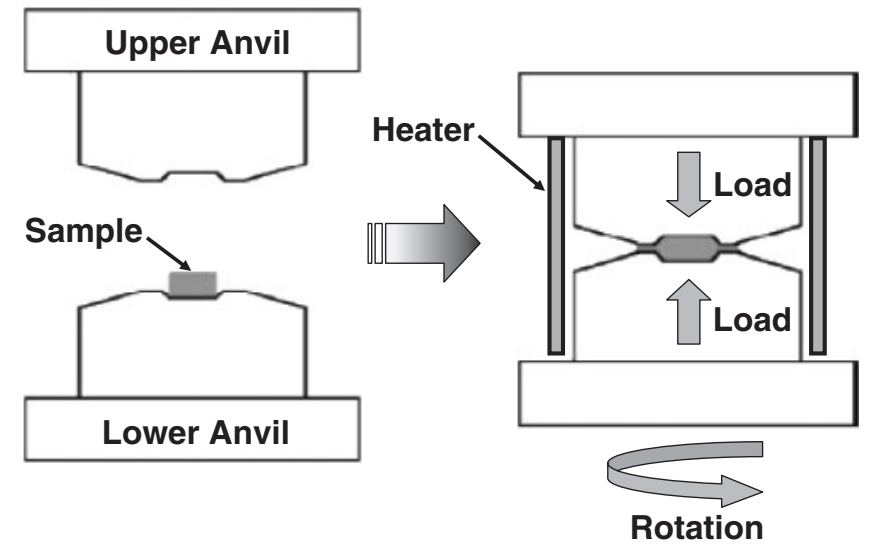

Fig. 2 Schematic illustration of the HPT facility showing the assembly on the left and torsional straining at an elevated temperature on the right.

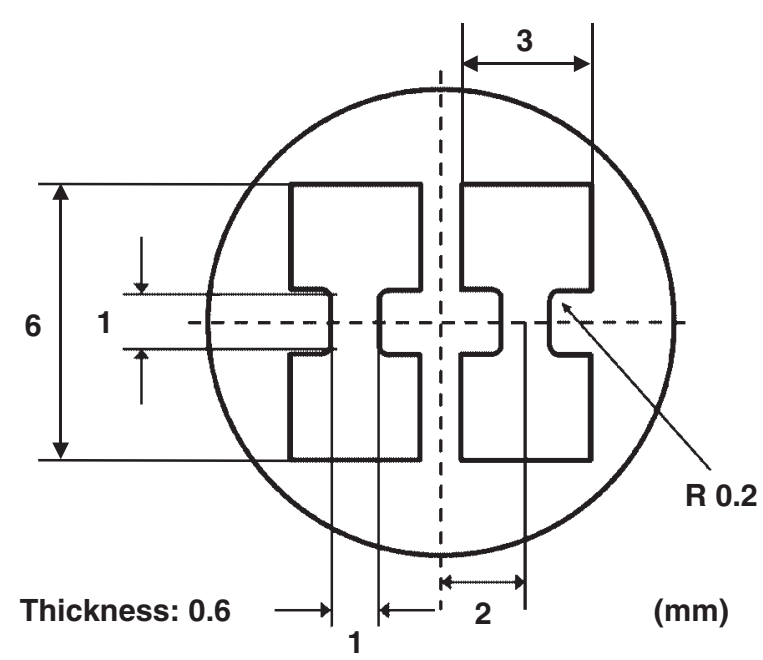

Fig. 3 Plan view of an HPT disk showing the locations and dimensions of tensile specimens cut from off-center positions after torsional straining.

$2 \pi N r / h \sqrt{ } 3$, where $N$ is the total number of turns and $r$ and $h$ locate positions in the disk in terms of the radius and height, respectively. ${ }^{22)}$ It follows from this expression that the strain varies across the disk and therefore it is important to take measurements of the local hardness across the disk diameters. In the present investigation, measurements of the Vickers microhardness, $\mathrm{Hv}$, were recorded at intervals of $0.5 \mathrm{~mm}$ from the center to the edge of each disk using an applied load of $50 \mathrm{~g}$ and a dwell time of $15 \mathrm{~s}$.

Following HPT, each disk was ground to a thickness of $0.6 \mathrm{~mm}$ and then tensile samples were cut from the disks with two samples located in each disk and, as in an earlier report, ${ }^{13)}$ the samples were situated in off-center positions to avoid possible inhomogeneities near the disk centers. Specifically, the central lines of the tensile specimens were located at a distance of $2 \mathrm{~mm}$ from a line passing through the center of the disk, as illustrated schematically in Fig. 3. These samples were pulled in tension using a testing machine operating at a constant rate of cross-head displacement and with initial strain rates in the range from $3.3 \times 10^{-4}$ to $3.3 \times 10^{-2} \mathrm{~s}^{-1}$. Tensile testing was conducted at 423 and $473 \mathrm{~K}$ after processing by HPT through $1,3,5$ and 7 turns, respectively. 


\section{Position of observation}

\section{Number of turns}

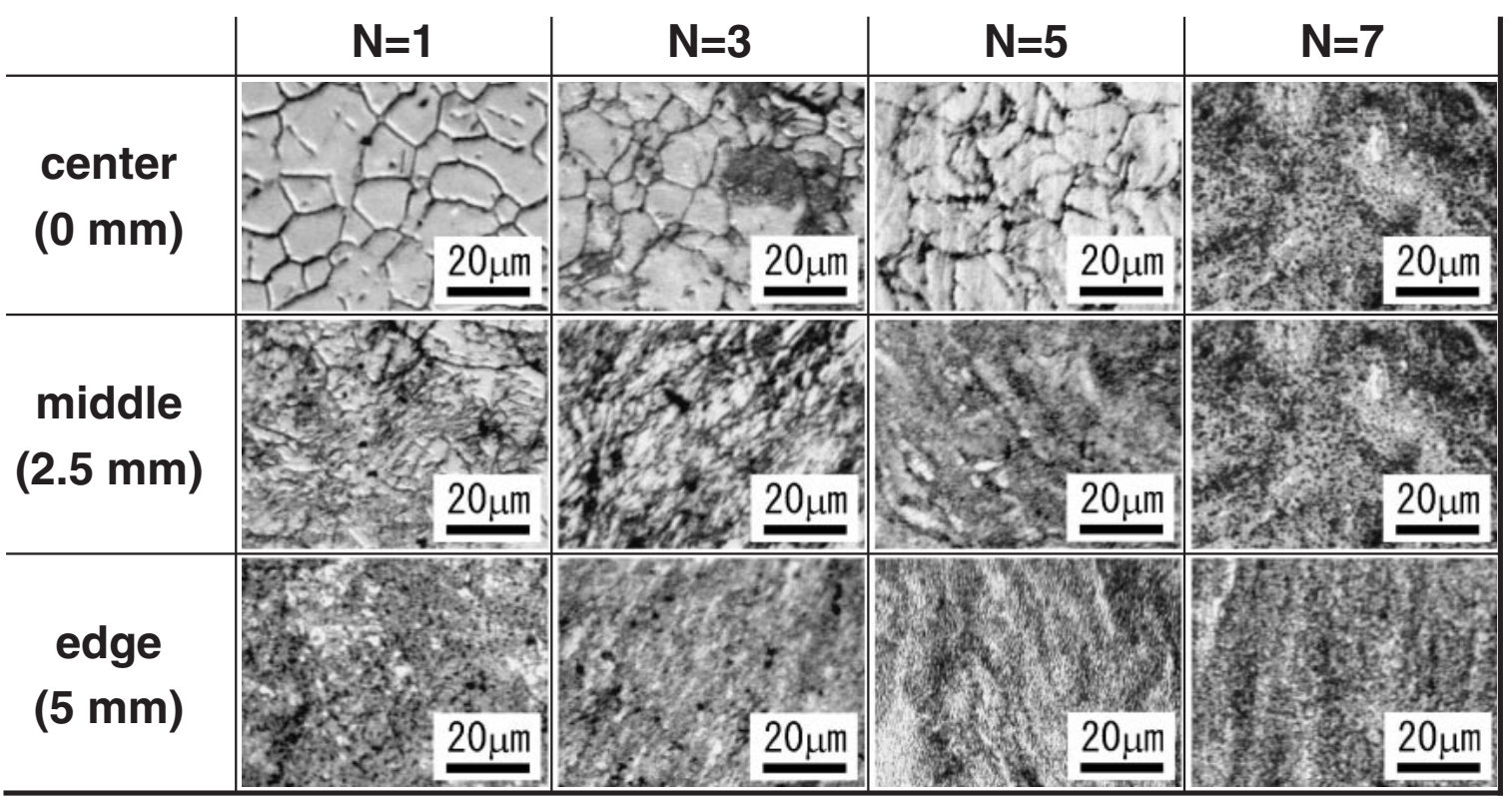

(distance from center)

Fig. 4 Optical micrographs showing the microstructures after HPT at the center, half-way position and edge of each disk after processing through $1,3,5$ and 7 turns at a temperature of $423 \mathrm{~K}$.

Samples were examined after processing by HPT process and after tensile testing using both optical microscopy (OM) and transmission electron microcopy (TEM). For OM, the HPT samples were ground mechanically, polished electrochemically using a solution of $10 \mathrm{ml}$ of $\mathrm{HCl}, 10 \mathrm{ml}$ of $\mathrm{HNO}_{3}$ and $160 \mathrm{ml}$ of $\mathrm{C}_{2} \mathrm{H}_{5} \mathrm{OH}$ and etched chemically using a solution of $4.2 \mathrm{~g}$ of $\mathrm{C}_{6} \mathrm{H}_{3} \mathrm{~N}_{3} \mathrm{O}_{7}, 10 \mathrm{ml}$ of $\mathrm{CH}_{3} \mathrm{COOH}, 10 \mathrm{ml}$ of $\mathrm{H}_{2} \mathrm{O}$ and $160 \mathrm{ml}$ of $\mathrm{C}_{2} \mathrm{H}_{5} \mathrm{OH}$. For TEM, disks having diameters of $3 \mathrm{~mm}$ were cut from the HPT samples using an electro-discharge machine. The disk centers were situated at $2 \mathrm{~mm}$ from the centers of the HPT sample and the microstructures were therefore observed at locations corresponding to the gauge sections of the tensile specimens. These disks were ground mechanically to a thickness of $0.15 \mathrm{~mm}$ and polished electro-chemically using a twin-jet apparatus with a solution of $15 \mathrm{ml}$ of $\mathrm{HClO}_{4}, 15 \mathrm{ml}$ of $\mathrm{HOCH}_{2} \mathrm{CH}(\mathrm{OH}) \mathrm{CH}_{2} \mathrm{OH}$ and $70 \mathrm{ml}$ of $\mathrm{C}_{2} \mathrm{H}_{5} \mathrm{OH}$. All values of the average grain sizes were measured from micrographs using the conventional linear intercept method.

\section{Experimental Results}

\subsection{Microstructural characteristics after HPT}

Processing by HPT is complex because the imposed strain varies both with the number of revolutions applied to the sample and with the position within the disk. The variations in microstructures attained in the AZ61 alloy after HPT at $423 \mathrm{~K}$ are documented by the optical micrographs in Fig. 4 which show typical microstructures at the centers, half-way positions and the edges of the disks after processing through 1, 3, 5 and 7 turns. The corresponding TEM micrographs for the same samples are shown in Fig. 5 in bright-field (on the left) and dark-field (on the right) together with the associated selected area electron diffraction (SAED) patterns taken from regions having diameters of $2.3 \mu \mathrm{m}$; as noted earlier, these TEM images were taken at approximately $2 \mathrm{~mm}$ from the centers of the HPT disks.

It is readily apparent from inspection of Fig. 4 that the microstructure develops more rapidly at the edge of the disk so that fewer turns are needed to achieve significant grain refinement. On the other hand, the optical micrographs taken in the center of the disk show an evolution towards an ultrafine-grained microstructure that is reasonably similar to the microstructure at the edge. There is also an evolution in the appearance by TEM such that the grains are better defined after larger numbers of turns. The dark-field images in Fig. 5 show clearly that the microstructures consist of ultrafinegrains. Furthermore, based on the rings visible in the SAED patterns, these grains are separated by boundaries having high angles of misorientation. It is also apparent that the average grain size was relatively large after a single turn but decreased with increasing numbers of turns.

Measurements of the average grain sizes for these samples gave the results plotted in Fig. 6. Thus, the average grain size was reduced to $0.52 \mu \mathrm{m}$ after one turn and it was further reduced to 0.37 and $0.23 \mu \mathrm{m}$ after 3 and 5 turns, respectively. Thereafter, the microstructure appeared reasonably stable and the measured grain size after 7 turns was $0.22 \mu \mathrm{m}$. By comparison, as shown in Fig. 7 with bight-field images and dark-field images including SAED patterns, processing through 5 turns of HPT gave grain sizes of $0.11 \mu \mathrm{m}$ at room temperature and $0.25 \mu \mathrm{m}$ at $373 \mathrm{~K}$ thereby demonstrating that 

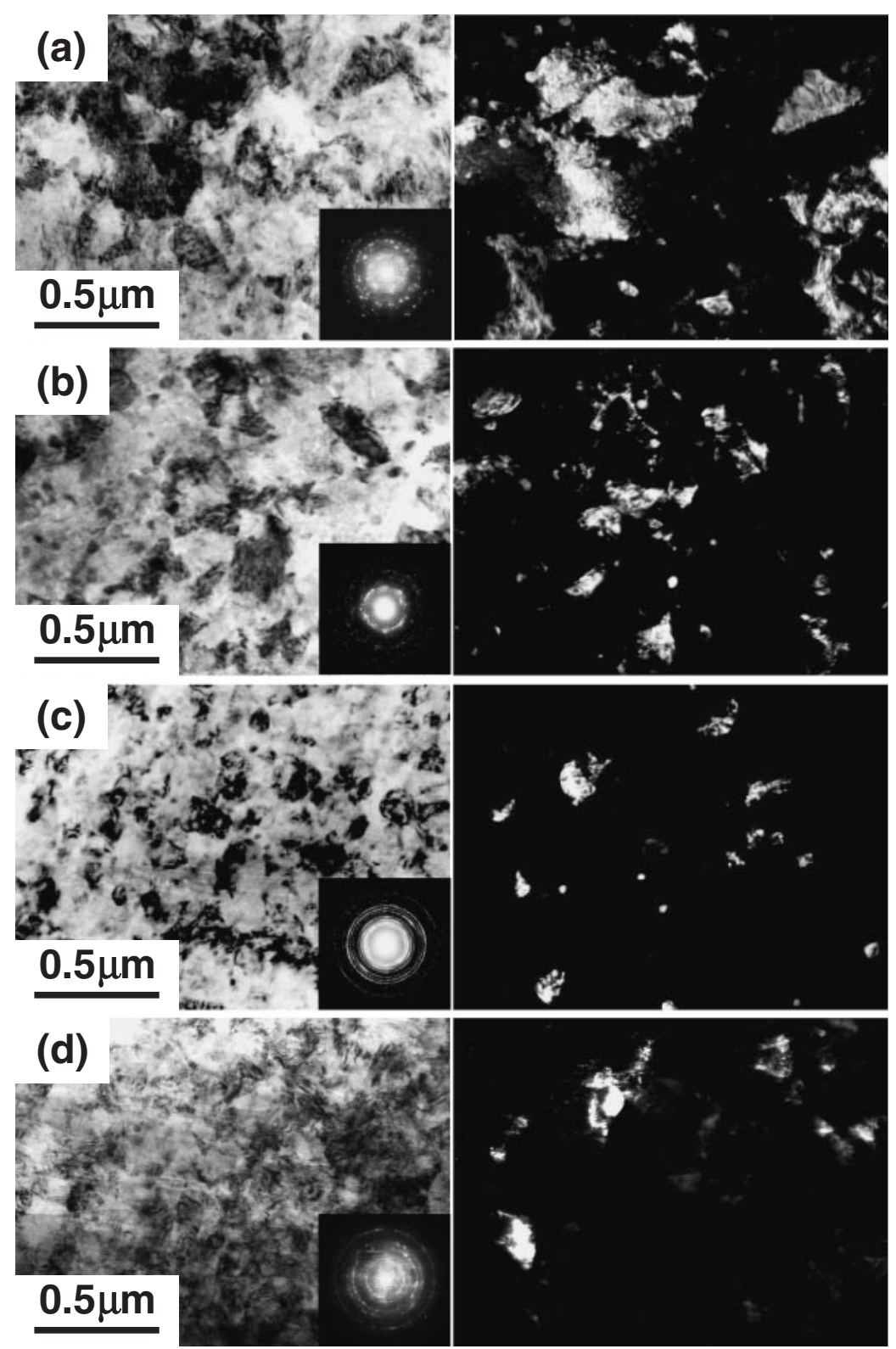

Fig. 5 Equivalent TEM micrographs in bright-field (left) and dark-field (right), plus the associated SAED patterns, after HPT at $423 \mathrm{~K}$ through 1, 3, 5 and 7 turns: these images were taken at $\sim 2 \mathrm{~mm}$ from the centers of the disks.

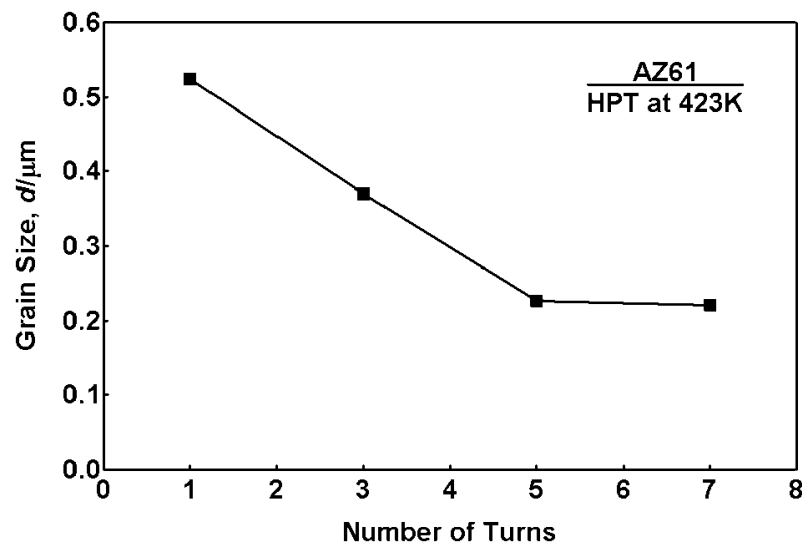

Fig. 6 Average grain size versus number of turns after HPT at $423 \mathrm{~K}$. smaller grain are achieved when processing at lower temperatures. The dark-field image shown in Fig. 7(a) clearly demonstrates that the grain size is reduced significantly when pressing at room temperature. It is significant also to note that the AZ61 alloy was successfully processed in this investigation through up to 5 turns at room temperature although subsequent tensile testing, described in the following section, suggested that some internal cracking may have been introduced at this relatively low processing temperature.

Figure 8 shows the variation across the radius of the disk of the Vickers microhardness, $\mathrm{Hv}$, for the as-received condition in the absence of HPT and after 1, 3, 5 and 7 turns at $423 \mathrm{~K}$. As anticipated from earlier investigations, the hardness increases across the disk in the first turn but with a significantly lower hardness measured in the central region. ${ }^{423)}$ Nevertheless, the hardness values become more uniform with additional turns and after 7 turns the values of 

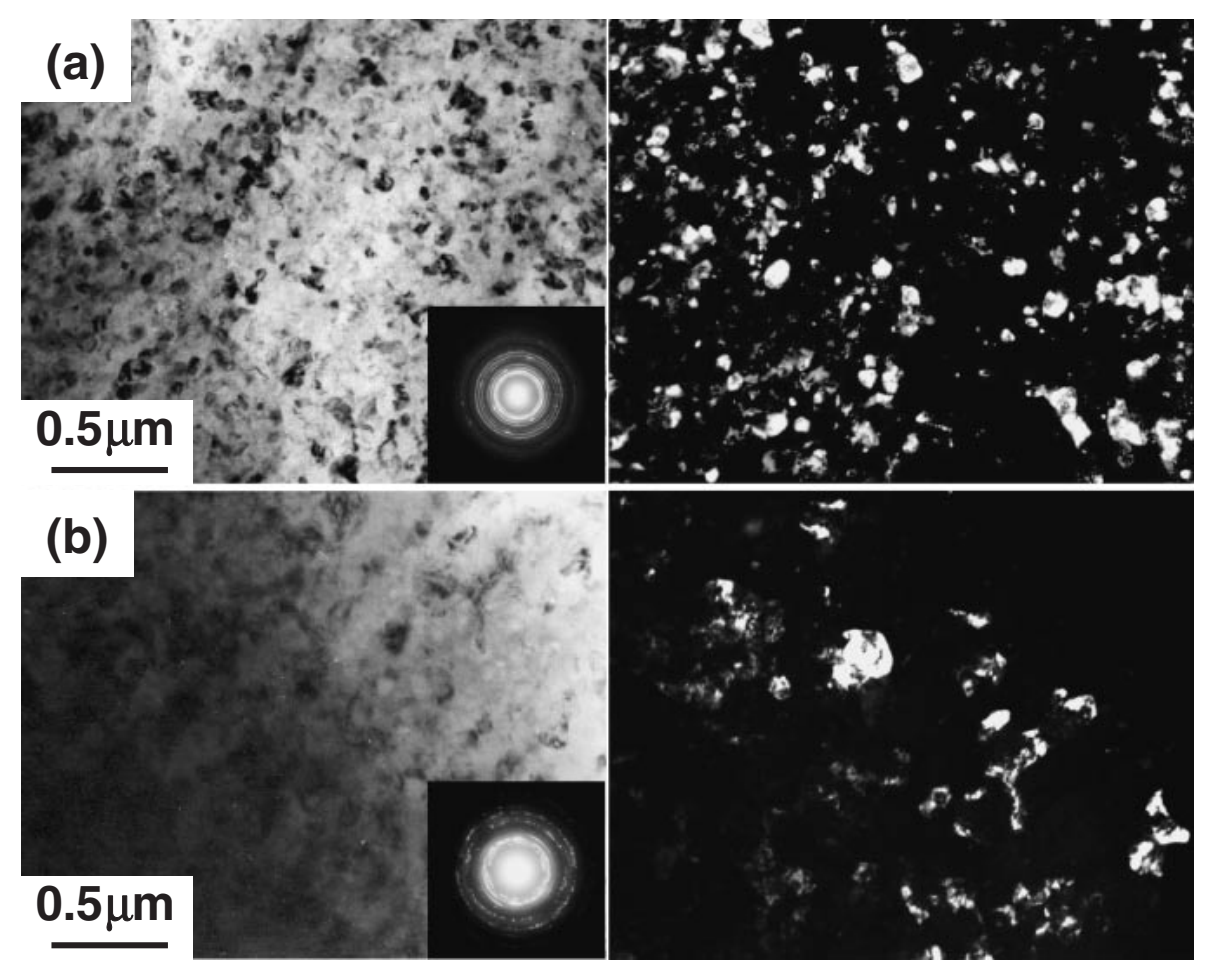

Fig. 7 Micrographs in TEM in bight-field (left) and dark-field (right), and the associated SAED patterns, after processing through 5 turns at (a) room temperature and (b) $373 \mathrm{~K}$.

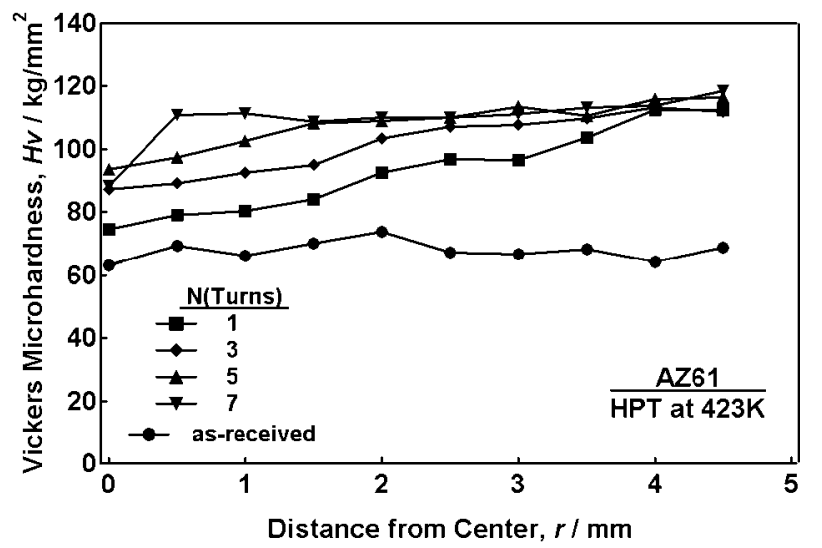

Fig. 8 Values of the Vickers microhardness across the radii of disks in the as-received condition and after processing through 1, 3, 5 and 7 turns at $423 \mathrm{~K}$.

$\mathrm{Hv}$ are essentially constant except only in the precise center of the disk. This gradual evolution towards homogeneity is consistent with an earlier report of hardness measurements taken on samples of pure $\mathrm{Al}$ processed by HPT. ${ }^{24)}$

\subsection{Mechanical properties after HPT}

It was recognized in early investigations of ECAP that superplastic ductilities can be achieved after processing only when the ultrafine grains are separated by boundaries having high angles of misorientation and the grains are reasonably stable at elevated temperatures. ${ }^{25)}$ To check on the grain stability, samples were prepared by HPT through 5 turns at a processing temperature of $423 \mathrm{~K}$ and they were annealed for 1 hour at temperatures from 300 to $523 \mathrm{~K}$. The measured grain sizes are shown in Fig. 9 and it is apparent that there

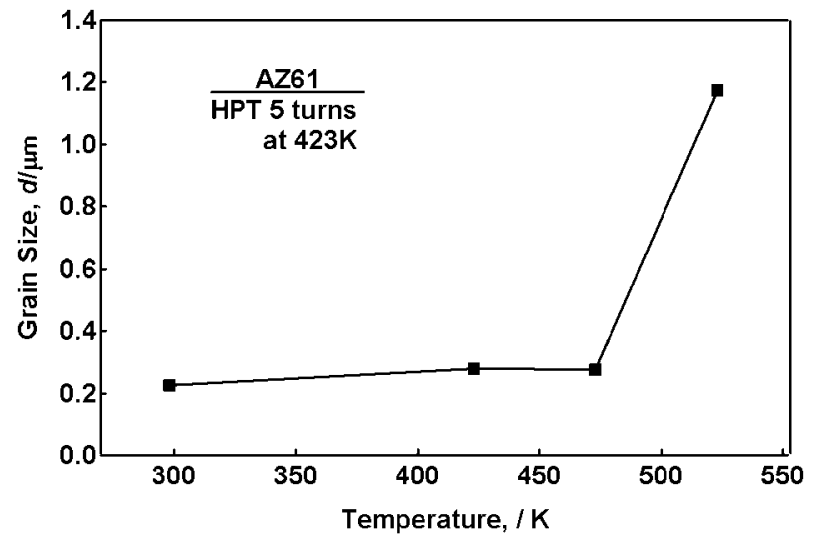

Fig. 9 Measured grain size versus annealing temperature for AZ61 processed by HPT through 5 turns at $423 \mathrm{~K}$ and then annealed for 1 hour at selected temperatures.

is excellent grain stability up to a temperature of $473 \mathrm{~K}$ but at $523 \mathrm{~K}$ there is significant grain growth to an average value of $\sim 1.2 \mu \mathrm{m}$. These results suggest that superplastic ductilities may be attained at a tensile testing temperature of $473 \mathrm{~K}$.

To check the viability of this conclusion, Fig. 10 shows plots of nominal stress against elongation for samples processed at $423 \mathrm{~K}$ through 5 turns and then pulled to failure at different temperatures using an initial strain rate of $3.3 \times 10^{-3} \mathrm{~s}^{-1}$. As anticipated, good ductility was achieved at $473 \mathrm{~K}$ but there was a reduction in the ductility at $523 \mathrm{~K}$ and lower ductilities were attained when the samples were tested at lower temperatures. The appearance of these specimens is shown in Fig. 11 where the upper specimen is untested and the highest measured elongation of $620 \%$ was 


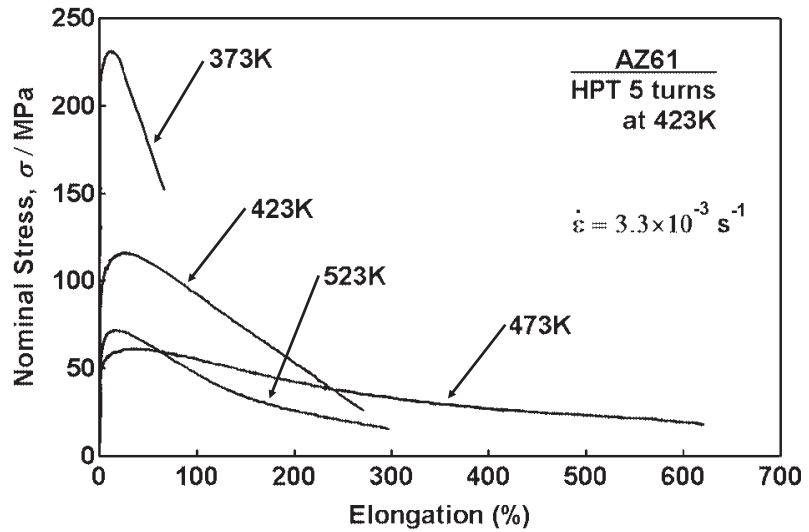

Fig. 10 Nominal stress versus elongation for tensile specimens processed by HPT through 5 turns at $423 \mathrm{~K}$ and then pulled to failure at different temperatures using an initial strain rate of $3.3 \times 10^{-3} \mathrm{~s}^{-1}$.

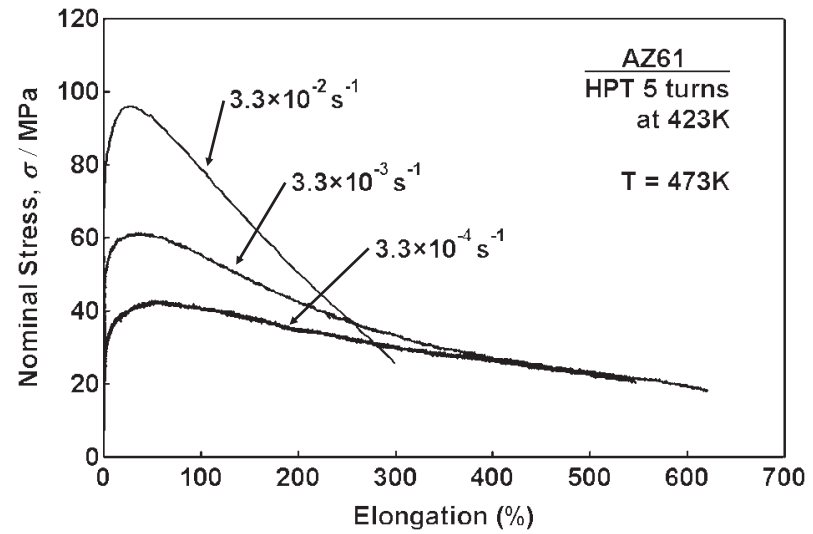

Fig. 12 Nominal stress versus elongation for tensile specimens processed by HPT through 5 turns at $423 \mathrm{~K}$ and then pulled to failure at different strain rates at a temperature of $473 \mathrm{~K}$.

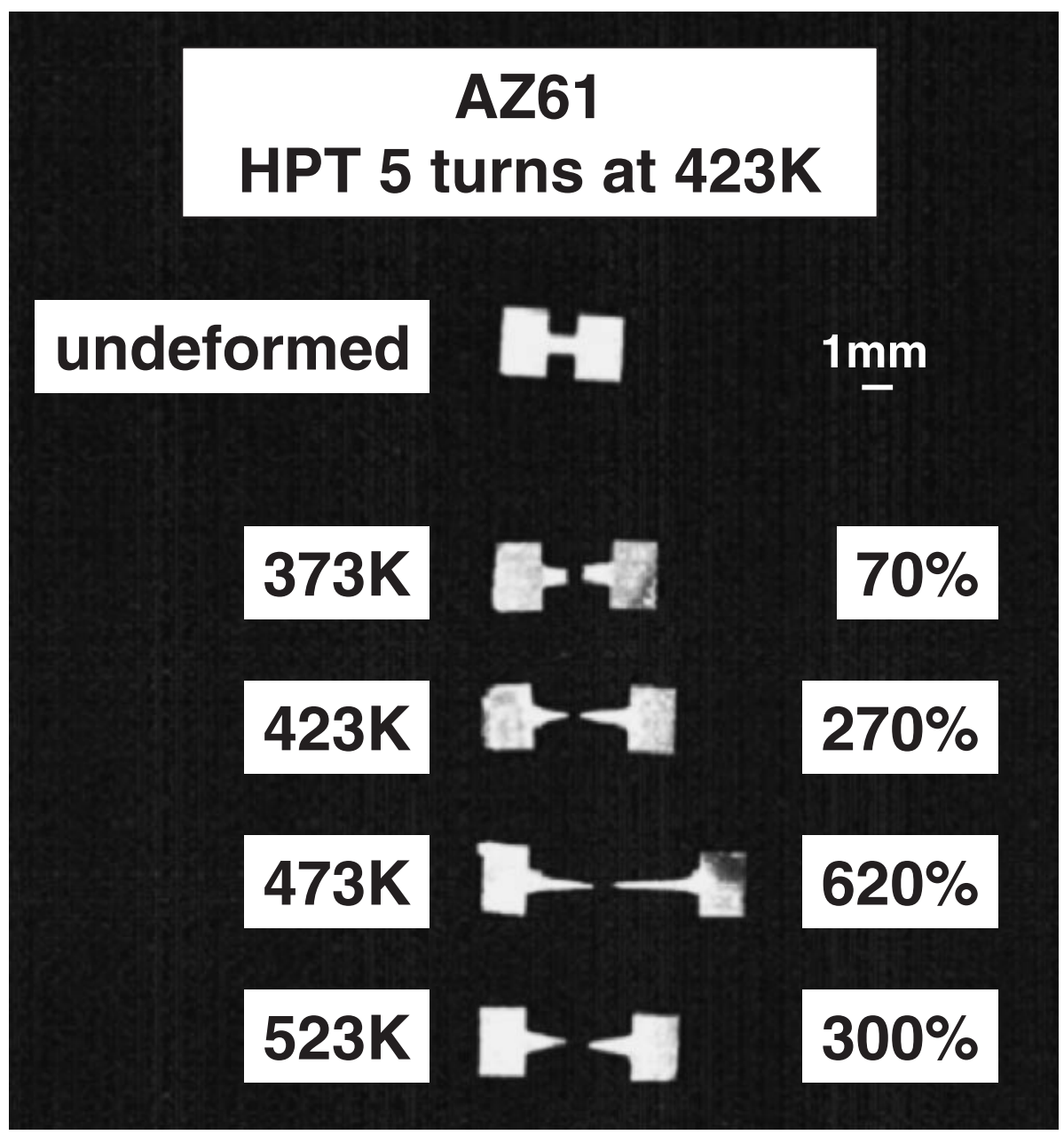

Fig. 11 Appearance of tensile specimens after processing through 5 turns at $423 \mathrm{~K}$ and then pulling to failure at temperatures from 373 to $523 \mathrm{~K}$ : the upper specimen is untested.

attained at $473 \mathrm{~K}$. This elongation is within the superplastic range which is generally considered as elongations at and above $\left.500 \% .{ }^{9}\right)$

It appears that the elongation of $620 \%$ recorded in Fig. 11 is probably close to the optimum value because, as documented in Fig. 12, lower elongations are observed when pulling similar samples at either faster or slower strain rates. This is consistent with the characteristic of superplastic flow in conventional alloys where superplasticity occurs over a limited range of strain rates and there is a loss in ductility at both faster and slower rates. ${ }^{26,27)}$ It was possible to estimate the strain rate sensitivity of the AZ61 alloy using the flow stresses at a nominal strain of $\sim 0.1$ and this gave a value of $\sim 0.3$. In practice, this is consistent with an earlier study where a similar strain rate sensitivity of $\sim 0.3$ was reported for the same alloy after processing by ECAP. ${ }^{16)}$ 


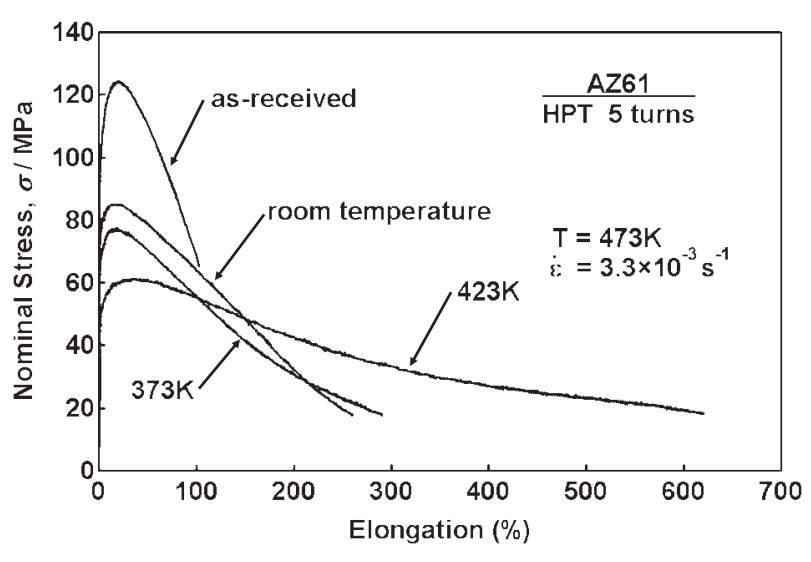

Fig. 13 Nominal stress versus elongation for tensile specimens processed by HPT through 5 turns at different temperatures and then pulled to failure at $473 \mathrm{~K}$ using an initial strain rate of $3.3 \times 10^{-3} \mathrm{~s}^{-1}$.

It appears from these results that a processing temperature of $423 \mathrm{~K}$ for HPT is probably close to the optimum condition for achieving superplastic flow in this alloy because, as shown in Fig. 13, lower elongations were achieved at $473 \mathrm{~K}$ when specimens were processed by HPT at either room temperature or $373 \mathrm{~K}$ : also included in Fig. 13 is a stressstrain curve for the as-received condition in the absence of HPT where the elongation to failure was $\sim 100 \%$. Despite the fact that the average grain size tends to be smaller after processing at room temperature as shown in Fig. 7, it is apparent that the elongation recorded in Fig. 13 for this condition is rather low. This apparent dichotomy is probably due to the presence of some limited internal cracking which may be introduced when conducting HPT processing at lower operating temperatures. Finally, testing at an initial strain rate of $3.3 \times 10^{-3} \mathrm{~s}^{-1}$ at $473 \mathrm{~K}$ gave elongations of $190 \%$ and $260 \%$ for samples processed by HPT at $423 \mathrm{~K}$ through 1 and 3 turns thereby demonstrating that high strains are required in order to achieve optimum superplastic flow. A similar result was reported earlier for samples of an Al-Mg-Sc alloy processed by ECAP through different numbers of passes. ${ }^{28)}$

\section{Discussion}

There are several important results from this investigation.

First, excellent ultrafine-grained microstructures were achieved in the magnesium AZ61 alloy after processing by HPT. The measured equilibrium grain sizes were $\sim 0.22 \mu \mathrm{m}$ after HPT at $423 \mathrm{~K}$ and $\sim 0.11 \mu \mathrm{m}$ after HPT at room temperature. These grain sizes are significantly smaller than the reports of average grain sizes of $\sim 1.35$ and $\sim 0.62 \mu \mathrm{m}$ after processing of the AZ61 alloy by ECAP at temperatures of 523 and $473 \mathrm{~K}$, respectively. ${ }^{16)}$ Thus, it is reasonable to conclude that HPT is a preferable procedure for producing extremely small grains.

Second, the results show that the imposition of an applied pressure during torsional straining permits the effective use of HPT at relatively low temperatures because the deformation process is then comparable to processing by ECAP in the presence of a back-pressure. Thus, HPT was successfully conducted at room temperature in the present investigation although this relatively low temperature gave rise to the introduction of some limited internal cracking.

Third, excellent superplastic ductilities were achieved in the AZ61 alloy after processing by HPT and the maximum recorded elongation of $620 \%$ is higher than the maximum elongations achieved in earlier studies using samples of aluminum alloys after processing by HPT. ${ }^{13,14)}$ The ability to attain high elongations in the present work, despite using a magnesium-based alloy where tensile ductility is generally limited, is attributed to the exceptionally fine grain sizes produced by HPT.

Fourth, and most important, the results confirm earlier studies of a gradual microstructural evolution during torsional straining in HPT such that there is the development of an essentially homogeneous microstructure with increasing numbers of turns. ${ }^{4,24,29)}$ This microstructural evolution was successfully interpreted recently using two complementary variants of a strain gradient plasticity model in which it was shown that a relatively uniform microstructure will develop across an HPT disk during continuous torsional straining. Furthermore, this homogeneity is predicted within the model despite the inherently non-uniform nature of the straining process. ${ }^{30)}$ It follows therefore that the experimental results, together with the associated theoretical interpretation, are important because they provide a clear demonstration of the feasibility of using the HPT processing technique to achieve reasonable levels of homogeneity and accordingly to produce materials that may be effectively used in commercial applications.

\section{Summary and Conclusions}

(1) An AZ61 magnesium alloy was successfully processed by High-Pressure Torsion over a range of temperatures from room temperature to $423 \mathrm{~K}$. Excellent grain refinement was achieved with average equilibrium grain sizes of $\sim 0.22$ and $\sim 0.11 \mu \mathrm{m}$ after HPT at $423 \mathrm{~K}$ and room temperature, respectively.

(2) Good ductilities were achieved in tensile testing after HPT with a maximum superplastic elongation of $620 \%$ in a specimen processed through 5 turns at $423 \mathrm{~K}$ and then tested in tension at $473 \mathrm{~K}$ using an initial strain rate of $3.3 \times$ $10^{-3} \mathrm{~s}^{-1}$.

(3) Microhardness measurements demonstrate that, although there was initially a lower hardness in the central region of the disks processed by HPT, there was a gradual evolution towards a reasonably homogeneous structure with increasing numbers of turns and hence with increasing torsional strain.

\section{Acknowledgments}

This work was supported in part by the Light Metals Educational Foundation of Japan, in part by a Grant-in-Aid for Scientific Research from the Ministry of Education, Culture, Sports, Science and Technology, Japan, on Priority Areas "Giant Straining Process for Advanced Materials Containing Ultra-High Density Lattice Defects" and in part by the National Science Foundation of the United States under Grant No. DMR-0243331. 


\section{REFERENCES}

1) R. Z. Valiev, Y. Estrin, Z. Horita, T. G. Langdon, M. J. Zehetbauer and Y. T. Zhu: JOM 58(4) (2006) 33.

2) R. Z. Valiev, R. K. Islamgaliev and I. V. Alexander: Prog. Mater. Sci. 45 (2000) 103-189.

3) R. Z. Valiev and T. G. Langdon: Prog. Mater. Sci. 51 (2006) 881-981.

4) A. P. Zhilyaev, G. V. Nurislamova, B.-K. Kim, M. D. Baró, J. A. Szpunar and T. G. Langdon: Acta Mater. 51 (2003) 753-765.

5) Y. Saito, N. Tsuji, H. Utsunomiya, T. Sakai and R. G. Hong: Scripta Mater. 39 (1998) 1221-1227.

6) Z. Horita and T. G. Langdon: Mater. Sci. Eng., A 410-411 (2005) 422 425.

7) J. Dutkiewicz, J. Kaśnierz, W. Maziarz, M. Lejkowska, H. Garbacz, M. Lewandowska, A. V. Dobromyslov and K. J. Karzydlowski: Phys. Status Solidi A 202 (2005) 2309-2320.

8) R. Z. Valiev, D. A. Salimonenko, N. K. Tsenev, P. B. Berbon and T. G. Langdon: Scripta Mater. 37 (1997) 1945-1950.

9) M. Kawasaki and T. G. Langdon: J. Mater. Sci. 42 (2007) 1782-1796

10) R. Z. Abdulov, R. Z. Valiev and N. A. Krasilnikov: J. Mater. Sci. Lett. 9 (1990) 1445-1447.

11) R. B. Figueiredo, P. R. Cetlin and T. G. Langdon: Acta Mater. (2007) (in press).

12) K. Xia, J. T. Wang, X. Wu, G. Chen and M. Gurvan: Mater. Sci. Eng., A 410-411 (2005) 324-327.

13) G. Sakai, Z. Horita and T. G. Langdon: Mater. Sci. Eng., A 393 (2005) 344-351.

14) S. V. Dobatkin, E. N. Bastarache, G. Sakai, T. Fujita, Z. Horita and T. G. Langdon: Mater. Sci. Eng., A 408 (2005) 141-146.

15) Y. Yoshida, K. Arai, S. Itoh, S. Kamado and Y. Kojima: Mater. Trans.
45 (2004) 2537-2541.

16) Y. Miyahara, Z. Horita and T. G. Langdon: Mater. Sci. Eng., A 420 (2006) 240-244.

17) A. Yamashita, Z. Horita and T. G. Langdon: Mater. Sci. Eng., A 300 (2001) 142-147.

18) Z. Horita, K. Matsubara, K. Makii and T. G. Langdon: Scripta Mater. 47 (2002) 255-260.

19) K. Matsubara, Y. Miyahara, Z. Horita and T. G. Langdon: Acta Mater. 51 (2003) 3073-3084.

20) A. P. Zhilyaev, K. Oh-ishi, T. G. Langdon and T. R. McNelley: Mater. Sci. Eng., A 410-411 (2005) 277-280.

21) A. P. Zhilyaev, T. R. McNelley and T. G. Langdon: J. Mater. Sci. 42 (2007) 1517-1528.

22) F. Wetscher, A. Vorhauer, R. Stock and R. Pippan: Mater. Sci. Eng., A 387-389 (2004) 809-816.

23) A. P. Zhilyaev, S. Lee, G. V. Nurislamova, R. Z. Valiev and T. G. Langdon: Scripta Mater. 44 (2001) 2753-2758.

24) C. Xu, Z. Horita and T. G. Langdon: Acta Mater. 55 (2007) 203-212.

25) P. B. Berbon, M. Furukawa, Z. Horita, M. Nemoto, N. K. Tsenev, R. Z. Valiev and T. G. Langdon: Phil. Mag. Lett. 78 (1998) 313-318.

26) T. G. Langdon: Metall. Trans. A 13A (1982) 689-701.

27) C. Xu, Z. Horita, M. Furukawa and T. G. Langdon: J. Mater. Eng. Perform. 13 (2004) 683-690.

28) S. Komura, M. Furukawa, Z. Horita, M. Nemoto and T. G. Langdon: Mater. Sci. Eng., A 297 (2001) 111-118.

29) Yu. Ivanisenko, R. Z. Valiev and H.-J. Fecht: Mater. Sci. Eng., A 390 (2005) 159-165.

30) Y. Estrin, A. Molotnikov, C. H. J. Davies and R. Lapovok: J. Mech. Phys. Solids (2007) (submitted for publication). 